\title{
Patterns of radiographic abnormalities associated with basic calcium phosphate and calcium pyrophosphate dihydrate crystal deposition in the knee
}

\author{
PAUL B HALVERSON AND DANIEL J McCARTY \\ From the Division of Rheumatology, Medical college of Wisconsin, Milwaukee, WI, USA
}

SUMMARY Radiographs and synovial fluids from 66 knees representing 59 patients with symptomatic osteoarthritis were evaluated to determine the pattern of radiographic abnormalities associated with basic calcium phosphate (BCP), calcium pyrophosphate dihydrate (CPPD), or both crystals together. Crystals were found in $71 \%$ of fluids. In general, CPPD crystals correlated with patient age, while BCP crystals correlated with joint degeneration. Synovial fluid BCP and CPPD crystals were found together more often than either alone. Joint compartment narrowing and osteophytes in three compartments are often associated with BCP crystals.

Key words: knee osteoarthritis, radiographic changes.

Basic calcium phosphate crystals $(\mathrm{BCP})$ (carbonate substituted hydroxyapatite, octacalcium phosphate, and tricalcium phosphate ${ }^{1}$ ) are associated with various conditions including Milwaukee shoulder syndrome, calcific periarthritis, and an erosive polyarticular arthropathy. ${ }^{2-4}$ Reports from three different laboratories have correlated the radiological severity of knee joint degeneration with the quantity of BCP crystals in joint fluid. ${ }^{5-7}$ The prevalence of crystals in joint fluid was also directly correlated with the extent of devolutionary changes noted radiographically. ${ }^{5} 8$ The pattern of radiographic abnormalities as correlated with the presence or absence of $\mathrm{BCP}$ and/or calcium pyrophosphate dihydrate (CPPD) crystals in 66 knee joint fluids from a series of 59 patients with symptomatic osteoarthritis is reported here.

\section{Materials and methods}

All patients were seen because of knee joint symptoms in the rheumatology clinics staffed by the full time faculty of the Medical College of Wiscon$\sin$. Patients were included only if synovial fluid was

Accepted for publication 19 December 1985.

Correspondence to Dr Paul B Halverson, Division of Rheumatology, Medical College of Wisconsin, 2900 West Oklahoma Avenue, Milwaukee, Wisconsin 53215, USA. obtained for crystal identification and radiographs were available. Synovial fluids were examined by compensated polarised light microscopy, and leucocyte counts were determined as described elsewhere. ${ }^{9}$ BCP crystals were identified by the binding of radiolabelled diphosphonate, followed by scanning electron microscopy with energy dispersive analysis to determine the calcium to phosphorus molar ratio as described previously.' Anteroposterior and lateral radiographs of the knees were read blindly by both authors. The presence of joint space narrowing and osteophytes in each of the three (medial and lateral tibiofemoral and patellofemoral) compartments of the knee was recorded. The presence of chondrocalcinosis and femoral cortical erosions (on lateral films) was also noted. Typical osteochondromata or soft tissue calcifications were noted. The Wilcoxon non-parametric ranked sums test was used for statistical comparison of patients ages. $\chi^{2}$ Analysis was used to evaluate radiologic findings.

\section{Results}

Complete studies were available on 66 knees in 59 patients. Seven patients had fluid aspirated from both knees, and the crystals populations indentified were concordant in all seven. All synovial fluids had 
Table 1 Synovial fluid crystals and patient characteristics

\begin{tabular}{lllll}
\hline & \multicolumn{3}{l}{ Group, crystals } \\
\cline { 2 - 5 } & $\begin{array}{l}\text { A, } \\
\text { none }\end{array}$ & $\begin{array}{l}B, \\
B C P\end{array}$ & $\begin{array}{l}C P P D \\
C P\end{array}$ & $\begin{array}{l}D, B C P \text { and } \\
C P P D\end{array}$ \\
\hline No of patients & 19 & 14 & 8 & 18 \\
No of knee joints & 19 & 17 & 8 & 22 \\
Mean age (years) & $68 \cdot 2$ & $66 \cdot 7$ & $74 \cdot 1$ & $75 \cdot 4$ \\
Range & $56-92$ & $49-96$ & $47-96$ & $52-80$ \\
M/F & $2 / 17$ & $3 / 11$ & $3 / 5$ & $9 / 9$ \\
\hline
\end{tabular}

total leucocyte counts less than $2000 \mathrm{~mm}^{3}\left(2 \times 10^{4} / \mathrm{l}\right)$ and were, therefore, of the 'non-inflammatory' group as defined by Ropes and Bauer. ${ }^{10}$ Each fluid was assigned to one of four groups according to the types of crystals found (Table 1). Forty seven of 66 fluids contained BCP or CPPD crystals, or both $(71 \%)$. Patients whose fluids contained both BCP and CPPD crystals (group D) were significantly older than those whose fluids contained no detectable crystals (group A) $(p<0 \cdot 01)$, and also older than those with BCP crystals only (group B) $(p<0 \cdot 01)$. Sex distribution between the various groups was not equal. No reason was found to explain the female predominance in group $\mathrm{A}$.

Abnormalities were detected in nearly all radiographs as summarised in Table 2 . The most severe radiographic changes were associated with $\mathrm{BCP}$ crystals or with BCP and CPPD together. Joint space narrowing was present in at least one compart-

Table 2 Radiographic features of 66 knees related to crystal species present in synovial fluid

\begin{tabular}{|c|c|c|c|c|}
\hline & \multicolumn{4}{|c|}{ Group, crystals } \\
\hline & $\begin{array}{l}\text { A. } \\
\text { none }\end{array}$ & $\begin{array}{l}B, \\
B C P\end{array}$ & $\begin{array}{l}C, \\
C P P D\end{array}$ & $\begin{array}{l}D, B C P \text { and } \\
C P P D\end{array}$ \\
\hline No of patients & 19 & 14 & 8 & 18 \\
\hline No of knee joints & 19 & 17 & 8 & 22 \\
\hline \multicolumn{5}{|l|}{$\begin{array}{l}\text { No of joint compartments } \\
\text { narrowed }\end{array}$} \\
\hline 0 & 5 & 2 & 2 & 1 \\
\hline 1 & 8 & 6 & 5 & 6 \\
\hline 2 & 6 & 8 & 0 & 13 \\
\hline 3 & 0 & 1 & 1 & 2 \\
\hline \multicolumn{5}{|l|}{ Three compartment } \\
\hline osteophytosis & 5 & 11 & 1 & 13 \\
\hline Chondrocalcinosis & 2 & 0 & 7 & $\begin{array}{r}10 \text { definite } \\
4 \text { possible }\end{array}$ \\
\hline Osteochondromata & 2 & 3 & 0 & 4 \\
\hline \multicolumn{5}{|l|}{ Soft tissue/tendon } \\
\hline calcification & 0 & 2 & 0 & 6 \\
\hline Femoral cortical erosion & 0 & 0 & 0 & 4 \\
\hline
\end{tabular}

ment in $15 / 17$ knees in group B and $21 / 22$ knees in group $\mathrm{D}$. The presence of diffuse osteophytosis involving all three knee compartments was found in $11 / 17$ with BCP crystals alone and $13 / 22$ with both BCP and CPPD. This was observed in only $1 / 8$ with CPPD alone and 5/19 with no crystals.

The groups were subdivided according to joint space narrowing in none or one compartment compared with narrowing in two or three compartments (interpreted to represent greater joint damage). Significantly greater joint damage was found in group D compared with group $A(p<0.025)$ or group $C(p<0.01)$, but no difference in joint degeneration was noted when groups $B$ and $C$ were compared $(0 \cdot 05<\mathrm{p}<0 \cdot 10)$.

Ten of the 18 patients in group D (BCP and CPPD) had definite and four had possible radiological chondrocalcinosis. None of the patients with BCP crystals alone had chondrocalcinosis.

Osteochondromata were found in a few patients in each group except group C. Femoral cortical erosions were found only in four patients, all of whom were in group D. One patient in each of groups $\mathrm{A}, \mathrm{B}$, and $\mathrm{D}$ also had the Milwaukee shoulder syndrome.

\section{Discussion}

It has been well established that both the presence and the concentration of BCP crystals in joint fluid correlate with radiological evidence of joint degeneration. ${ }^{5-8}$ Further, CPPD crystal deposition in cartilage is clearly related to age per se. ${ }^{11}$ The findings in the present study provide additional confirmation of both of these statements in a single population with symptomatic osteoarthritis of the knee. Joints with fluids containing only CPPD crystals showed no greater degree of radiographic degeneration than did joints with fluids containing no crystals at all, though these patients were older. If degeneration of one or more knee compartments coincides with CPPD deposition there is a great likelihood that synovial fluid BCP crystals will also be found.

The aetiology of BCP and CPPD deposition in articular tissues and their role in the pathogenesis of destructive changes in cartilage and subchondral bone remain unknown. Synthetic hydroxyapatite crystals are inflammatory, ${ }^{12}{ }^{13}$ but synovial fluids containing BCP crystals have no higher total leucocyte counts than those without. ${ }^{8} 14$ Dieppe and his associates have speculated that $\mathrm{BCP}$ crystals may act as a positive feedback loop to amplify the destructive process. ${ }^{15}$ In Milwaukee shoulder syndrome BCP crystals have been associated with extensive joint destruction in all cases. Neutral protease and 
collagenase activities were often found in these fluids, and BCP crystals stimulated both synthesis and secretion of these enzymes from tissue cultured synovial fibroblasts. This mechanism may represent one such positive feedback loop. ${ }^{16}$

The simultaneous occurrence of BCP and CPPD has been previously reported as 'mixed crystal disease'. ${ }^{17}{ }^{8}$ In the present study $18 / 40(45 \%)$ of fluids containing crystals had 'mixed crystal disease'. Gibilisco and his associates found an incidence of $43 \%$ and patients with radiological evidence of chondrocalcinosis were excluded from this study population. ${ }^{8}$ Thus the prevalence of both BCP and CPPD crystals together is more common than the prevalence of either type of crystal alone.

Identification of BCP crystals remains difficult. According to Paul et al alizarin red staining is a highly sensitive but non-specific screening procedure. ${ }^{6}$ Its clinical usefulness without more specific confirmatory methods remains uncertain. ${ }^{7}$ The $\left[{ }^{14} \mathrm{C}\right]$ ethane-l-hydroxy-1, l-diphosphonate $(\mathrm{EH}-$ DP) binding test is sensitive to $2 \mu \mathrm{g}$ of standard hydroxyapatite crystals $/ \mathrm{ml}$. Concentrations of crystals not detectable by $\left[{ }^{14} \mathrm{C}\right] \mathrm{EHDP}$ binding may give positive results by alizarin red staining, making comparison of our data with other published results difficult.

In a previous study of 11 patients with Milwaukee shoulder syndrome we found that seven had involvement of their knees as well. The abnormalities were not those of typical osteoarthritis in that three had lateral rather than medial compartment narrowing and five had chondrocalcinosis. Three patients in the present study had shoulder abnormalities compatible with Milwaukee shoulder syndrome. One of these knees had lateral compartment narrowing and another had chondrocalcinosis. The question of whether or not the radiological pattern of knee joint degeneration is distinctive in patients with Milwaukee shoulder syndrome cannot be answered from the data presented here but will require further study.

In summary, crystals are often present in synovial fluid from osteoarthritic joints. There is no distinctive pattern of radiographic abnormality that accompanies BCP crystal deposition, but the presence of knee joint compartment narrowing, particularly in the presence of three compartment osteophytosis, is very suggestive. The findings are similar when both $\mathrm{BCP}$ and CPPD are present except that radiological chondrocalcinosis is often seen. Joint fluid BCP crystals appear to correlate mainly with devolutionary joint changes, while CPPD crystals in joint fluid appear to correlate chiefly with age.

\section{References}

1 McCarty D J, Halverson P B. Basic calcium phosphate (apatite, octacalcium phosphate, tricalcium phosphate) crystal deposition disease. In: McCarty D J, ed. Arthritis and allied conditions. 10th ed. Philadelphia: Lea and Febiger, 1985: $1547-64$.

2 Halverson P B, McCarty D J, Cheung H S, Ryan L M. Milwaukee shoulder syndrome: eleven additional cases with involvement of the knee in seven (basic calcium phosphate crystal deposition disease). Semin Arthritis Rheum 1984; 14: $36-44$.

3 Faure G, Daclusi G. Calcified tendonitis: a review. Ann Rheum Dis 1983; 42: 50-3.

4 Schumacher H R, Miller J L. Ludvico C. Jesser R A. Erosive arthritis associated with apatite crystal deposition. Arthritis Rheum 1981; 24: 31-7.

5 Halverson P B. McCarty D J. Identification of hydroxyapatite crystals in synovial fluid. Arthritis Rheum 1979; 22: 389-95.

6 Paul H, Reginato A J, Schumacher H R. Alizarin red S staining as a screening test to detect calcium compounds in synovial fluid. Arthritis Rheum 1983; 26: 191-200).

7 Bardin T, Bucki B, Dryll A, Lansaman J. Ryckewaert A. Alizarin red staining of synovial fluid (SF). Similar results in osteoarthritis (OA) and rheumatoid arthritis (RA). Arthritis Rheum 1985; 28 (suppl): S53.

8 Gibilisco P A. Schumacher H R, Hollander J L, Soper K A. Synovial fluid crystals in ostcoarthritis. Arthritis Rheum 1985: 28: 511-5.

9 McCarty D J. Synovial fluid. In: McCarty D J, ed. Arthritis and allied conditions. 10th ed. Philadelphia: Lea and Febiger. 1985: $54-75$.

10 Ropes M W, Bauer W. Synovial fluid changes in joint diseases. Boston: Harvard University Press, 1953.

11 Ryan L M, McCarty D J. Calcium pyrophosphate crystal deposition disease; pseudogout; articular chrondrocalcinosis. In: McCarty D J, ed. Arthritis and allied conditions. 10th ed. Philadelphia: Lea and Febiger, 1985: 1515-46.

12 Dieppe P A, Crocker P, Huskisson E C, Willoughby D A. Apatite deposition disease: a new arthropathy. Lancet 1976; i: 266-9.

13 Schumacher H R, Smolyo A P, Tse R L, Maurer K. Arthritis associated with apatite crystals. Ann Intern Med 1977; 87: 411-6.

14 Dicppe P A, Crocker P R, Corke C F. Doyle D V. Huskisson E C. Willoughby D A. Synovial fluid crystals. $Q J$ Med 1979; 48: 533-53.

15 Dieppe P A. Doherty M, MacFarlane D G, Hutton C W. Bradfield J W, Watt I. Apatite associated destructive arthritis. Br J Rheumatol 1984; 23: 84-91.

16 Cheung H S, Halverson P B, McCarty D J. Garancis J C. Release of collagenase, neutral protease, and prostaglandins from cultured synovial cells by hydroxyapatite and calcium pyrophosphate dihydrate. Arthritis Rheum 1981; 24: 1338-44.

17 Dieppe P A, Doyle D V, Huskisson E C, Willoughby D A, Crocker P R. Mixed crystal deposition disease and osteoarthritis. $B r$ Med J 1978; i: 150.

18 Doylc D V. Dicppe P A, Crocker P R. Ibe K. Mixed crystal deposition in an ostecarthritic joint. J Pathol 1977: 123: 1-5. 